\title{
INTER-ETHNIC RELATIONS AMONG BLACK STUDENTS AT A SOUTH AFRICAN HIGHER EDUCATION INSTITUTION
}

\author{
M. A. Mulondo* \\ Department of Psychology \\ e-mail: mulondoma@ufs.ac.za / https://orcid.org/0000-0002-9178-3412
}

\author{
A. T. Thomas* \\ Department of Psychology \\ e-mail: angela.thomas@up.ac.za / https://orcid.org/0000-0002-1780-0915
}

*University of Pretoria

Pretoria, South Africa

\section{ABSTRACT}

This study explored the inter-ethnic relations and experiences of students at a higher education institution, using an exploratory case study approach. Purposive sampling was used to select students belonging to black South African ethnic groups. Semi-structured interviews were used to collect data from three participants; interpretative phenomenological analysis was used for analysis. The themes extracted were ethnic identity: identity confusion vs. certainty; personal experiences of inter-ethnic relations; and majority and minority ethnic groups' experiences. Identity salience was found to not particularly be integral to the cultivation of inter-ethnic relations. Moreover, participants' inter-ethnic experiences were varied; some were positive, and others, negative. Relations between majority and minority ethnic groups are seemingly supported by existing literature, as majority ethnic group members typically initiated negative interactions, more so than did minority ethnic groups. Future studies should interrogate inter-ethnic dynamics on a broader scale, and explore ethnic bullying and its impact on inter-ethnic relations.

Keywords: ethnic identity, higher education, identity, inter-ethnic relations, stereotypes, students

\section{INTRODUCTION}

Previous studies have mostly focused on interracial relations, particularly between black and white racial groups, whereas few have been conducted on inter-ethnic relations. This study focused on relations between members of black ethnic groups in South Africa, entailing an analysis of case studies of three black, ethnically diverse university students. According to Statistics South Africa (2011), South Africa has nine primary black ethnic groups. An ethnic group refers to an organized group of people who share a language and culture, and possibly work together to advance interests such as politics (Quaker-Dokubo 2001, 16). The nine black ethnic groups referred to above are Zulu, Xhosa, Sotho, Tswana, Ndebele, Tsonga, Venda, 
Swati and Pedi. Only a few of these ethnic groups could participate in the study. A tertiary institution might be the first opportunity for some students to closely interact with other ethnic groups. This might largely hold true for rural areas in South Africa, whereas the urban South African landscape, in contrast, tends to be ethnically diverse. These varying local contexts presumably have unique implications for the dynamics of inter-ethnic relations.

According to Swart et al.'s $(2010,309)$ study in South Africa, some individuals display prejudicial stances towards intergroup relations, as shown by their disapproval of such, whereas those who readily engage in such relations tend to be anxious due to the fear of victimization. However, this and a similar study in an Ethiopian university (Adamu 2013, 78) - with 83 indigenous ethnic groups - found that the more intergroup contact there was, the less prejudice there was and the more empathy was cultivated. The above studies support Allport's contact theory (Pettigrew 1997, 173); whose assumption is that the more people from different groups engage and interact with each other, the less they hold onto their prejudices. Additionally, students have been found to be optimistic about forming positive inter-ethnic relations (Semela 2012,337). These observations justify our study's focus on students' experiences of inter-ethnic relations in a racially and ethnically diverse tertiary institution. The study's focus is also in consideration of Chickering and Reisser's $(1993,339)$ argument that students in controlled environments such as college campuses face various crises that contribute towards the development of their self-concepts, which presumably includes ethnic identity development. Further, these authors posit that the search for identity is especially prominent among college students, compared to other populations, thereby suggesting that the university setting constitutes an important context for the formation of one's ethnic identity.

\section{LITERATURE REVIEW}

\section{The influence of self-identity and ethnic identity on inter-ethnic relations}

Goldschmidt $(2003,206)$ asserted that "[i]dentity is belonging to a group that provides people with a framework with which to articulate who they are". Additionally, Villar $(2011,13)$ states that people mostly define themselves according to their ethnicity and race. Ethnic identity, particularly among adolescents and young adults, is an important subject to explore, considering that according to Erikson, role confusion may occur when one's self-identity is not discovered (Dunkel and Sefcek, 2009, 14). In demonstration of this, Adamu's $(2013,88)$ abovementioned study in Ethiopia found that students from ethnically mixed groups experienced confusion when they had to choose a political party to align with based on ethnicity. Further, students who chose one ethnic group over another were ostracized by students from the 
seemingly non-preferred ethnic group, which led to strained ethnic relations. Victimization, ethnic discrimination and feelings of lack of belonging can further obstruct individuals' identity formation and psychosocial adjustment (Adamu 2013, 89; McKenney et al. 2006, 240). This is because, other than one's own ethnic self-identification, how peers perceive one's ethnic group also plays an important role in such identification (Gonzalez 2009, 18). Furthermore, according to Newman and Newman $(2014,6)$, individuals' interactions with their environment (e.g., family and society) ultimately reveal the influence that the latter may have on how they view and interact with the world. For example, a South African study found that individuals who had strong ties to their own ethnic groups found it easier to identify with members of other ethnic groups (Harris and Findley 2014, 6). Therefore, the inability to form or discover one's selfidentity may lead not only to identity confusion, but also to strained inter-ethnic relations and poor psychosocial adjustment. The latter is particularly important to consider in high-pressure environments such as tertiary education.

\section{Positive and negative inter-ethnic relations}

Ethnic relations among members of different ethnic groups may result in either predominantly positive or negative interactions. Vitoroulis, Brittain, and Vaillancourt $(2016,432)$ state that, "ethnic diversity inevitably leads to frequent inter-ethnic contact, which may result in positive or negative interactions between students." Positive interactions can take the form of good friendships and be marked by cordial relations. According to Adamu $(2013,82)$, the "[s]ocial bond that arises because of reasons like [...] living together is found to [contribute] to positive intergroup relations". Therefore, more positive contact among members of different ethnic groups, such as greeting members of a different ethnic group, students being open to sharing accommodation with members of different ethnic groups or to learning other ethnic groups' ways may cultivate positive inter-ethnic relations. On the contrary, Vitoroulis et al. $(2016,431)$ suggest that ethnic diversity in academic institutions has the potential to increase the possibility of victimization on the grounds of ethnicity. Further, according to Vitoroulis and Schneider $(2009,27)$, in settings with diverse social groups, in-group members tend to assign negative attributes to members of out-groups. These negative attributions may include direct forms of aggression such as taunts and slurs (Scherr and Larson 2009, 225), and derogatory references to culturally-specific customs (Wong 2009, 22). The negative ethnic interactions may also be exacerbated by stereotypes. Stereotypes inhibit genuine relations from forming and therefore perpetuate negative inter-ethnic relations. Other than possibly dispelling stereotypes about outgroup members, interactions between members of different ethnic groups have the potential to cultivate either positive or negative inter-ethnic relations, as observed by the above-mentioned authors. 


\section{Inter-ethnic relations among majority and minority ethnic groups}

Literature indicates that minority ethnic groups are usually at the receiving end of negative behavior from majority ethnic groups, with minority groups being shown to be more likely to experience victimization, as compared to majority groups (Cunniff and Mostert 2012, 4; Pryor and Fitzgerald 2003, 84; Vitoroulis and Schneider 2009, 29). Contrasting findings by Shapka and Law (2013, 735), Carlyle and Steinman (2007, 628), and Wang, Ianotti, and Nansel (2009, 368) found that ethnic minority students were more likely to victimize others. These discrepancies suggest that there are various context-specific factors that may give rise to either inclination. In view of this, the current study sought to explore not only participants' experiences of inter-ethnic relations in a South African tertiary education context, but also observe how majority and minority ethnic groups relate to one another (as informed by the broader South African context).

\section{METHODOLOGY}

\section{Research approach}

A qualitative research approach was chosen for this study, as it afforded us the opportunity to explore participants' subjective experiences of the phenomenon under study. Specifically, an exploratory case study design was adopted, in consideration of the scarcity of local research specifically on black students' experiences of inter-ethnic relations in ethnically diverse postapartheid higher education contexts. Exploratory case studies typically enable further exploration of the phenomenon under study in subsequent research (Zainal 2007, 3).

\section{Study setting, sampling and participants}

The South African tertiary institution selected as the study setting enrolls students from various backgrounds. The ratio of enrolled female to male students in the Faculty of Humanities - in which the study participants were enrolled - in the years 2017 and 2018 was 7:3, and that in 2019 was $4: 1$.

To recruit participants, posters were placed on notice boards at the relevant departments in the Humanities Faculty. Purposive sampling was applied, to allow the researchers to screen participants suitable for the study (Denscombe 2014, 32). In qualitative research, emphasis is not placed on the use of a large, representative sample, as the intention is not to generalize the findings. Rather, the onus is on the researcher to ensure that the sample selected meets the set criteria for participation, as per the study aim (Bock and Sergeant 2002, 1). The inclusion 
criteria were that participants belong to a black ethnic group, have experienced inter-ethnic relations at the tertiary institution under study, and be enrolled as students in the Faculty of Humanities. White students were excluded from participation, as the study specifically focused on inter-ethnic relations among members of black ethnic groups. Those willing to participate could contact one of the researchers telephonically, who would then confirm if volunteers met the set criteria before participation. Six students responded to the poster advert. Three of the six respondents were excluded for the following reasons: one had just de-registered as a student to pursue a professional career, and the other two were not reachable for interviews after numerous attempts were made to reach them. Ultimately, three students took part in the study. Of the three participants, two were female, and one male. Of the two female participants, one belonged to the Pedi ethnic group, and was a part-time student enrolled for Master's studies at the time of the study. The second female participant was an ethnically mixed (Tswana and Swati) first-year student from a low-middle socio-economic background. This participant's studies were funded by the National Student Financial Aid Scheme (NSFAS), which provides funding to students from low- and low-middle income families. The third participant was male, from the Xhosa ethnic group. This participant had just passed his final-year exams in respect of undergraduate studies and was self-reportedly from a high socio-economic background.

\section{Data collection}

Participants were interviewed by the first author in a quiet room at the institution under study. A semi-structured interview guide comprising open-ended questions was used to collect the data. The questions asked sought to elicit responses regarding participants' inter-ethnic experiences at the institution. Interviews were audio-recorded and, subsequently, manually transcribed (Evers 2011, 21). The interview guide comprised questions such as:

1. How do you feel about being a member of your ethnic group?

2. Have you had any positive personal experiences with a member of another black South African ethnic group?

3. If yes, please elaborate on the experience and the person's ethnic group.

4. Would you say that this positive encounter enhanced or changed your perspective of that person's ethnic group?

5. Have you had any negative personal experiences with a member of another black South African ethnic group?

6. If yes, please elaborate on the experience and the person's ethnic group.

7. Would you say that this negative encounter enhanced or changed your perspective of that 
person's ethnic group?

\section{Data analysis and interpretation}

Interpretative phenomenological analysis (IPA) was used to analyze the data (Smith 2011, 9), allowing the researcher to identify themes from the data collected. IPA, as defined by Smith $(2011,9)$, "is concerned with the detailed examination of personal lived experience, the meaning of experience to participants and how participants make sense of that experience". Codes were developed and subsequently grouped into themes. In the interpretation of findings, both similarities and differences between participants' experiences in the themes extracted were noted (Smith 2011, 24). The study findings were analyzed by the first author, while the coauthor cross-checked the findings against the data, verifying the appropriateness of the assigned codes and themes.

\section{Trustworthiness and subjectivity}

Trustworthiness refers to aligning the researcher's conclusion with what the participant actually said and meant (Guba 1981, 79). Trustworthiness was ensured through the interviewer's (also one of the researchers') repetition of interviewees' statements during the interview, for clarity, and through probing questions, to facilitate elaboration by participants and, therefore, clarity of their views. The interviewer avoided personal bias by remaining neutral and separating preconceived ideas from those presented by participants.

\section{ETHICAL CONSIDERATIONS}

The study was approved by the Faculty of Humanities Research Ethics Committee at the University of Pretoria. Each participant received an information sheet detailing what the study entailed. Participants were given an opportunity to ask questions for clarity, to enable them to give informed consent (Nishimura et al. 2013, 28). Participants could withdraw from the study at any time without penalty (Edwards 2005, 113). No financial or material incentives were offered to the participants, to minimize the possibility of coerced participation and, instead, to facilitate voluntary participation. Pseudonyms were also used in the interpretation of findings and all publicly available material.

Participants were also provided with the contact details of Student Support Services at the study site, in case they experienced distress as a result of participation in the study.

\section{RESULTS AND DISCUSSION}

The main themes extracted from this study were ethnic identity: identity confusion vs. certainty; 
personal experiences of inter-ethnic relations; as well as majority and minority ethnic groups' experiences. The theme on participants' personal experiences of inter-ethnic relations had subthemes pertaining to positive and negative experiences.

\section{Ethnic identity: identity confusion vs. certainty}

According to Erikson's psychosocial theory, identity formation refers to discovering the self, while role confusion refers to uncertainty when the self is not discovered (Dunkel and Sefcek 2009, 14). On the one hand, subscribing to Erikson's above-mentioned assumptions about identity formation, one of the participants, Kate, who is ethnically mixed (Tswana and Swati) experienced confusion as she struggled to decide which ethnic group to identify or align herself with:

"Uhm, this is gonna be very funny: I am not sure. Why I am saying I am not sure is my mother is Tswana, right? I know I can't be Tswana. But my father is Swati, but he doesn't speak Swati now. He speaks Zulu."

Due to being ethnically mixed and not being able to speak her father's language, Kate felt considerable pressure as she believed that her sociocultural context expected her to identify with her father's ethnic group. Other than the conceptualization of identity formation in terms of dichotomous stages, as per Erikson's (Dunkel and Sefcek 2009, 14) framework, Kate's concerns regarding expectations in the sociocultural context equally presuppose that identity formation is socially constructed (Torres, Jones, and Renn 2009, 577). These concerns subscribe to the social constructionist notion of identity as comprising beliefs about oneself in relation to the broader social context, which comprises social groups. Moreover, as ethnicity and language are known to be conflated in certain contexts (Adamu 2013, 86), it is understandable as to why the participant believed that she could not identify with her father's ethnic group, as she did not speak the language associated with this ethnic group. Her inability to form a self-identity coincided with negative inter-ethnic interactions with members of her father's ethnic group, as she felt left out if they did not include her in their conversations,

"On the bench, and probably a friend [Swati] is sitting right next to you and you happen to be in the middle and the other friend comes that side, and they converse like over you in their language that you don't know. They converse over you, because I am inquisitive, I will be like, 'what are you guys saying?' And they think you are rude; so, that is negative."

Her desire to fit in led to her interpretation of such exchanges as signifying negative ethnic relations. Despite its ostensibly negative outcomes for Kate at the time of the study, her reflection on her ethnic membership may signify what Phinney and Alipuria $(1990,171)$ refer 
to as exploration of one's ethnic identity. Phinney and Alipuria $(1990,171)$ found ethnic identity exploration to be higher among student members of minority ethnic groups, compared to the majority ethnic group. Kate's ethnic identity exploration patterns may reflect those of members of minority ethnic groups, possibly due to her self-construal as peculiar, due to confusion regarding her mixed ethnic background.

While Kate may have experienced ethnic confusion, one of the other participants in the study, Daniel, illustrated his positive identification with his ethnic group and its associated characteristics, as he stated, “... and so, I like being Xhosa. I love everything about being Xhosa and yeah, even our language ... it's nice. True, it is the South African French." Such a strong affinity towards one's ethnic group leads to clear distinctions between the in-group and outgroups (Kliot and Waterman 2015,2), which can be demonstrated by the defense of one's group from negative comments by out-groups, as illustrated by Daniel, “... I feel like we are mostly misunderstood because, especially in the political context ... If you are Xhosa, you are linked to ANC [the national ruling party], you are linked to greediness, you are linked to lying." In their South African study, Harris and Findley $(2014,6)$ found that individuals with strong ties could more easily identify with members of other ethnic groups. This was also illustrated by Daniel, “... Xhosa people are, oh mostly we love socializing with other ethnic groups, compared to Zulus". Although it might be true that individuals with strong ethnic ties may easily identify with other ethnic groups, our findings regarding minority groups contradicted Harris and Findley's $(2014,6)$, as evidenced by the following account from Kate, a member of a minority ethnic group:

'I met some lady and and she said, 'What language are you?', and I said, 'I am Tswana,' right? Because I am from Pretoria; re bolela SePitori. And I am like, 'I am Tswana.' And she was like, 'Oh, ndingumXhosa.' And I am like, 'Oh, can you teach me?' And she is like, 'Yes. So, what we will do ... we will exchange contacts and I will teach you how to say hello, and uh ... then step by step."

Thus, the current study findings show that individuals may still be able to form positive ethnic relations with members of other ethnic groups, in spite of the strength of their own ethnic ties.

\section{Positive and negative experiences of inter-ethnic relations}

\section{Positive experiences}

Participants had positive interactions with members of other ethnic groups. According to Adamu $(2013,78)$, most people get along better after getting to know each other, as illustrated by Bella, one of the participants, 
"when you hang around people of different ethnic groups for a while and become their friends, you tend to learn their language ... uhm ... and it makes communication also easier, and it breaks off that barrier that you have because if a person, an immediate person who can be able to explain to you what this means, how do you say [something in their language], how do you greet, or ... you know, etc., and as time goes on you really learn the language."

As illustrated above, Bella also found learning other languages to be an additional advantage of positive inter-ethnic interactions.

Daniel also referred to the importance of learning each other's cultures,

"So, with them, I feel like when we interact, we learn a lot from each other because I feel like there is a lot of stigma especially attached to them, since they [Pedi speakers] are from the upper part of South Africa, since now even now I get to learn about their culture, how they do things, their values, why they do some of the things they do. So, in that way I am able to interact with them, in a less offensive way because I, uhm, we are different, I wouldn't lie to you, we are different. But with the differences, I feel that with my friends, we get to use those differences to interact in a more positive light."

Participants' positive experiences support the contact theory, which states that negative relations can be reduced through engagement and contact between different groups (Pettigrew 1997, 173). Indeed, more inter-ethnic exposure seems to have minimized resorts to common, negative stereotypes about members of other ethnic groups and, instead, fostered genuine interactions in which participants sought to learn about each other. During these, participants found that the negative stereotypes that they held about members of other ethnic groups were not true, as explained by Bella:

"Because ... I mean ... I would say part of me, yes, there are certain ones where you are like, 'no man ... I mean ... maybe these people [Zulu speakers] are not [as] rude [as] the way they have been explaining them'."

Daniel shared a similar viewpoint regarding members of other ethnic groups,

"But when it comes to Zulus, and then your Sothos, even Tswanas, I have come to find that Tswanas are actually the most gentlest people there, calm ... So, in that way, it is much easier to interact with them."

These examples from the participants further illustrate how with the opportunity to establish contact and engage, positive inter-ethnic relations can be cultivated. 


\section{Negative experiences}

Participants also reported experiences of negative inter-ethnic relations. For instance, stereotypes held by participants about other ethnic groups were evident in the study. In the previous section on ethnic identity, Daniel stated that just because he is Xhosa, members of other ethnic groups automatically associated him with negativity, “... I feel like we are mostly misunderstood because, especially in the political context ... If you are Xhosa, you are linked to ANC [the national ruling party], you are linked to greediness, you are linked to lying." Daniel reiterated that people would associate him with lying, even though he did not consider himself a liar. Such misattributions of his character to the stereotypical beliefs held about his ethnic group could have negative implications for the possibility of positive inter-ethnic relations between Daniel and members of other ethnic groups. Further demonstrating this, Kate found that the stereotypes associated with her ethnic group hampered positive inter-ethnic relations:

"And sometimes it gets uncomfortable because you tend now to also be conscious of that [different languages spoken by other ethnic groups] and whenever you are within a certain type of context you try to hold that back and just try to communicate in the language that is mostly used and understood."

Therefore, although interactions may result in the revision of negative perceptions regarding others (Pettigrew 1997, 174), ethnic stereotypes seem to negatively affect individuals' ethnic identification, such that they distance themselves from their ethnic groups when interacting with others (Armenta 2010, 95), as evidenced by Kate. However, Bella found that discussions of stereotypes held among members of different ethnic groups had positive outcomes:

“... we just talk about such things ... how, those stereotypes about it, that's how you get to know ... especially if you become friends, very close to the people, that's how you will learn other people's ethnic groups."

Despite negative inter-ethnic experiences, some participants were reluctant to generalize their negative experiences with one member of a given ethnic group to the rest of the ethnic group. For example, referring to his reaction to being victimized by members of other ethnic groups, Daniel stated,

"But I avoid doing that [generalizing], because I understand that as much as they can be Pedi, there are Pedi's in Joburg, there are Pedi's everywhere, there are Pedi's who are more calm, there are Pedi's who are. So therefore, I can't brush them with the same brush and be like, 'all of you are the same'."

The above observations, such as concern about others' appraisal of one's ethnic group and the 
negotiation of one's ethnic identification in order to assimilate, allude to students' perceived importance of peers in their self-appraisal as members of certain ethnic groups. This is in line with Chickering and Reisser's $(1993,328)$ suggestion that the higher education environment is important for identity formation among students. These authors further posited that identity formation is cultivated by, among others, confidence in one's ability to bond with others, understanding and tolerance and, therefore, openness and self-esteem. Thus, poor inter-ethnic relations seemingly undermine students' esteem in relation to themselves and their respective ethnic groups, thereby hampering an important milestone of their higher education experience (i.e., identity formation). Daniel's cautiousness to not generalize to an entire ethnic group suggests an attempt to the contrary.

\section{Inter-ethnic relations between majority and minority ethnic groups}

Interactions between majority and minority ethnic groups may have different outcomes for members of either group type, thus alluding to the subjectivity of human interactions. In the current study, although failing to explain how, Daniel stated that his ethnic group was superior to others, "The Ngunis are better; Zulus and Xhosas, we are better". Despite this apparent predisposition towards assumptions of superiority by members of majority groups, Vermeij, Van Duijn, and Baerveldt $(2009,230)$ state that these individuals prefer relationships with their ethnic peers. In contrast, ethnic minority students easily form and maintain inter- and intraethnic friendships, as illustrated by Kate, "Zulus, Xhosas ... uhm, ya; I had encounters with them and that's why I am even able to speak their language ...". This might be due to the unequal structural relations that dictate that, for example, members of national minority ethnic groups be fluent in majority groups' languages, especially in local contexts in which the former are a minority. This is in line with Torres et al.'s $(2009,584)$ stance that majority groups determine what is valued - in this instance, language. Similarly, Daniel's assumption of his ethnic superiority may represent majority groups' accordance of importance, or lack thereof, to various groups, by mere virtue of their majority status. These results seemingly support those of previous studies, indicating that minority ethnic groups more easily cultivate positive interethnic relations.

\section{Limitations and recommendations for future studies}

The current study included a bi-ethnic participant who identified as both Tswana and Swati because these were her parents' ethnicities. This proved to be a limitation, as the participant had unique experiences relative to other participants. Sample homogeneity would have allowed better contextualization of the study findings as pertaining to either a mono-ethnic or multi- 
ethnic sample. A recommendation for future research is to expand the topic to also focus on ethnic bullying. This is especially given the assumption of ethnic superiority by a member of a majority ethnic group, which was not shared by the other two participants who are considered ethnic minorities.

\section{CONCLUSION}

Although literature states that strong ethnic identity ties play a pivotal role in the formation of positive ethnic relations, the current findings showed that individuals with a weak ethnic identity can establish strong inter-ethnic relations. In addition, some of the participants' positive inter-ethnic interactions enabled them to learn about each other's ethnic groups and form new positive opinions about those. In conclusion, majority and minority ethnic groups' interactions were consistent with those described in literature, showing that minority ethnic groups easily form inter-ethnic relationships, which might be facilitated by their forced multilingualism, for practical intents and purposes. In contrast, majority ethnic groups tended to confine themselves to interactions with members of their own ethnic groups, thereby lessening the likelihood of their establishment of rewarding inter-ethnic relationships. These dynamics, coupled with the perceived or enacted superiority and inferiority of different ethnic groups, may especially undermine the experiences of ethnic-minority students in social and interpersonal contexts in higher education. Thus, higher education institutions must aim towards fostering inclusive institutional cultures that neither alienate ethnic-minority students nor recreate the ethnic intolerance that members of minority ethnic groups contend with in the broader society. Nonetheless, it is worth noting that the small sample size of three in this study precludes generalizations to, and assumptions or predictions about broader contexts. Instead, our study findings provide an interesting narrative from the participants, that opens up opportunities for future research to interrogate the dynamics of inter-ethnic relations in the higher education context on a broader scale.

\section{REFERENCES}

Adamu, A. Y. 2013. "Intergroup relations among ethnically diverse university students in Ethiopia." Journal of Education and Research 3(2): 77-95. doi: http://dx.doi.org/10.3126/jer.v3i2.8399.

Armenta, B. E. 2010. "Stereotype boost and stereotype threat effects: The moderating role of ethnic identification." Cultural Diversity and Ethnic Minority Psychology 16(1): 94-98.

Bock, T. and J. Sergeant. 2002. "Small sample market research." International Journal of Market Research 44(2): 1-7. https://doi.org/10.1177/147078530204400205.

Carlyle, K. E. and K. J. Steinman. 2007. "Demographic differences in the prevalence, co-occurrence, and correlates of adolescent bullying at school." Journal of School Health 77(9): 623-629. http://dx.doi.org/10.1111/j.1746-1561.2007.00242.x. 
Chickering, A. W. and L. Reisser. 1993. Education and identity. San Francisco: Jossey-Bass.

Cunniff, L. and K. Mostert. 2012. "Prevalence of workplace bullying of South African employees." South African Journal of Human Resource Management 10(1). doi: 10.4102/sajhrm.v10i1.450.

Denscombe, M. 2014. The good research guide for small-scale social research projects. Berkshire, UK: McGraw-Hill International.

Dunkel, C. S. and J. A. Sefcek. 2009. "Eriksonian lifespan theory and life history theory: An integration using the example of identity formation." Review of General Psychology 13(1): 13-23.

Edwards, S. J. 2005. "Research participation and the right to withdraw." Bioethics 19(2): 112-130.

Evers, J. C. 2011. "From the past into the future. How technological developments change our ways of data collection, transcription and analysis." Forum Qualitative Social Research 12(1): 1-31.

Goldschmidt, M. M. 2003. "Identifying labels among university students in the new South Africa: A retrospective study." Journal of Black Studies 34(2): 204-221. doi: 10.1177/0021934703255314.

Gonzalez, R. 2009. "Beyond affirmation: How the school context facilitates racial/ethnic identity among Mexican American adolescents." Hispanic Journal of Behavioral Sciences 31(1): 5-31.

Guba, E. G. 1981. "Criteria for assessing the trustworthiness of naturalistic inquiries." Educational Communication and Technology Journal 29(2): 75-91. doi: 10.1007/bf02766777.

Harris, A. S. and M. G. Findley. 2014. "Is ethnicity identifiable? Lessons from an experiment in South Africa." Journal of Conflict Resolution 58(1): 4-33. doi: 10.1177/0022002712459710.

Kliot, N. and S. Waterman. (Eds.). 2015. Pluralism and political geography: People, territory and state. USA: Routledge. doi: https://doi.org/10.4324/9781315660929.

McKenney, K. S., D. Pepler, W. Craig and J. Connolly. 2006. "Peer victimization and psychosocial adjustment: The experiences of Canadian immigrant youth." Electronic Journal of Research in Educational Psychology 9(4): 239-264.

Newman, B. M. and P. R. Newman. 2014. Development through life: A psychosocial approach. Boston, Massachusetts: Cengage Learning.

Nishimura, A., J. Carey, P. J. Erwin, J. C. Tilburt, M. H. Murad and J. B. McCormick. 2013. "Improving understanding in the research informed consent process: A systematic review of 54 interventions tested in randomized control trials." BMC Medical Ethics 14(1): 28.

Pettigrew, T. F. 1997. "Generalized intergroup contact effects on prejudice." Personality and Social Psychology Bulletin 23(2): 173-185.

Phinney, J. S. and L. L. Alipuria. 1990. "Ethnic identity in college students from four ethnic groups." Journal of Adolescence 13(2): 171-183.

Pryor, J. P. and L. F. Fitzgerald. 2003. "Sexual harassment research in the United States." In Bullying and emotional abuse in the workplace: International perspectives in research and practice ed. S. Einarsen, H. Hoel, D. Zapf, and C. Cooper, 79-100. London: Taylor and Francis.

Quaker-Dokubo, C. 2001. "A Nigerian case study". Politics of identity and exclusion in Africa: From violent confrontation to peaceful cooperation, 43-56. Paper presented at a conference at the University of Pretoria, South Africa, 25-26 July. https://www.kas.de/wf/doc/kas 5094-544-230.pdf.

Scherr, T. G. and J. Larson. 2009. "Bullying dynamics associated with race, ethnicity, and immigration status." In Handbook of Bullying in Schools: An International Perspective, ed. S. R. Jimerson, S. M. Swearer and D. L. Espelage, 223-234. New York, New York: Routledge.

Semela, T. 2012. "Intergroup relations among the Ethiopian youth: Effects of ethnicity, language, and religious background." Journal of Developing Societies 28(3): 323-354.

Shapka, J. D. and D. M. Law. 2013. "Does one size fit all? Ethnic differences in parenting behaviors and motivations for adolescent engagement in cyberbullying." Journal of Youth and Adolescence 42(5): 723-738. doi:10.1007/s10964-013-9928-2.

Smith, J. A. 2011. "Evaluating the contribution of interpretative phenomenological analysis." Health 
Psychology Review 5(1): 9-27. doi: 10.1080/17437199.2010.510659.

Statistics South Africa. 2011. "South African Population Census." http://interactive.statssa.gov.za/ superweb/loadDatabase.do?db=Language11_wd (Accessed 5 September 2014).

Swart, H., M. Hewstone, O. Christ, and A. Voci. 2010. "The impact of crossgroup friendships in South Africa: Affective mediators and multigroup comparisons." Journal of Social Issues 66(2): 309333.

Torres, V., S. R. Jones, and K. A. Renn. 2009. "Identity development theories in student affairs: Origins, current status, and new approaches." Journal of College Student Development 50(6): 577-596.

Vermeij, L., M. A. Van Duijn, and C. Baerveldt. 2009. "Ethnic segregation in context: Social discrimination among native Dutch pupils and their ethnic minority classmates." Social Networks 31(4): 230-239. doi:10.1016/j.socnet.2009.06.002.

Villar, C. D. 2011. "Bullying, ethnic discrimination, or both? A phenomenological study of the experiences of immigrant adolescents." Unpublished Master's dissertation. Toronto: University of Toronto.

Vitoroulis, I., H. Brittain, and T. Vaillancourt. 2016. "School ethnic composition and bullying in Canadian schools." International Journal of Behavioral Development 40(5): 431-441. doi: $10.1177 / 0165025415603490$.

Vitoroulis, I. and B. H. Schneider. 2009. "Bullying and victimization of immigrant youth: A literature review." Report submitted to CERIS Working Papers Series. ceris.ca/wp-content/uploads/virtuallibrary/Schneider_et_al_2008.pdf (Accessed 2 August 2017).

Wang, J., R. J. Iannotti, and T. R. Nansel. 2009. "School bullying among adolescents in the United States: Physical, verbal, relational, and cyber." Journal of Adolescent Health 45(4): 368-375.

Wong, A. H. 2009. "The prevalence of ethnicity-related victimization in urban multiethnic schools." $\mathrm{PhD}$ thesis. Toronto: University of Toronto.

Zainal, Z. 2007. "Case study as a research method." Journal Kemanusiaan 5(1): 1-6. 